\title{
Factor Analysis of a Novel Scoring-Based Instrument on Forecasting Malaysian Travelers' Behavioral Preparedness for Travel-Related Infectious Diseases
}

\author{
Muhammad Haikal Ghazali'1*, Shamsul Azhar Shah', Mohd Ihsani Mahmood' \\ ${ }^{1}$ Department of Community Health, Universiti Kebangsaan Malaysia Medical Centre (UKMMC), Kuala Lumpur, \\ Malaysia
}

Corresponding Author: Muhammad Haikal Ghazali, PhD Candidate, Department of Community Health, Universiti Kebangsaan Malaysia Medical Centre (UKMMC), Jalan Yaacob Latiff, Bandar Tun Razak, 56000 Cheras, Kuala

Lumpur, Malaysia. Tel: +60-0177494584, Email: drhaikalghazali@gmail.com

Received April 6, 2018; Accepted April 25, 2018; Online Published May 9, 2018

\begin{abstract}
Introduction: Preparedness for the prevention of travel-related infectious diseases among Malaysian international travelers has yet to be explored. With no such data, health programs to empower travelers on behavioral responses towards travel-related illnesses will be ineffective. The current study aimed to develop and validate a new scoring-based instrument measuring Malaysian international travelers' preparedness in terms of their risk perception (RP), attitude, and practices (RisPAK-Q) towards travel-related infectious diseases using factor analysis.

Methods: The newly developed instrument was tested among 200 Malaysian international travelers based on the systematic random sampling method. The number of domains, model-fit index, construct validity, and internal consistency for this instrument were determined using exploratory and confirmatory factor analysis (CFA).

Results: Twenty-two out of 34 questions were retained, and the following 5 domains were extracted: RP, pre-travel attitude (PTA), duringtravel attitude (DTA), general traveling practice, and food practice (FP). All 22 questions had factor loadings of above 0.6. All 5 domains achieved a stable model fit index with good convergent and discriminant construct validity of above 0.5 indicated by the average variance extracted (AVE) with all of the maximum shared variance (MSV) values below their corresponding AVEs. All domains also had high internal consistency with a composite reliability (CR) of above 0.7 .

Conclusion: The RisPAK-Q containing 22 questions in 5 domains is a valid and reliable instrument for measuring the preparedness of Malaysian travelers for travel-related infectious diseases and can be used in a subsequent larger study.

Keywords: Factor Analysis, Infectious Disease, Travel Health, Validation, Malaysia
\end{abstract}

Citation: Ghazali MH, Shah SA, Mahmood MI. Factor analysis of a novel scoring-based instrument on forecasting Malaysian travelers' behavioral preparedness for travel-related infectious diseases. Int J Travel Med Glob Health. 2018;6(2):54-63. doi:10.15171/ijtmgh.2018.11.

\section{Introduction}

Traveling and the spread of infectious diseases are closely related. ${ }^{1}$ The World Tourism Organization (UNWTO) has reported that 1.235 billion people worldwide were involved in international travel in 2017, an increase of 46 million people from 2016. ${ }^{2,3}$ While traveling put the travelers at risk of being inflicted with travel-related illnesses, particularly infectious diseases, ${ }^{4,5}$ the increase in international travel over recent years could portend an increase in the spread of infectious diseases, both emerging and re-emerging ones, ${ }^{6,7}$ in the near future. . $^{1,5}$

Travel health service has therefore played an important role in managing the risk preventatively by educating and instilling standard travel-related health behavior in travelers by equipping them with awareness and preparedness on selfpreventive actions for travel-related illnesses, particularly infectious diseases. ${ }^{8,9}$ Unlike other developed countries which have extensive travel health services and actively deliver travel health educational programs to their travelers, ${ }^{10}$ Malaysia is among several countries that have yet to offer such services. With no background data on how Malaysian travelers behave towards travel-related illnesses, a travel health service designed to deliver systematic and structured preventive educational programs could not be effectively established. Realizing the importance of addressing this issue methodologically, a scoring-based instrument for measuring

Copyright $\odot 2018$ The Author(s). This is an open-access article distributed under the terms of the Creative Commons Attribution License (http:// creativecommons.org/licenses/by/4.0), which permits unrestricted use, distribution, and reproduction in any medium, provided the original work is properly cited. 
the attributes of preparedness for travel-related infectious diseases was developed as a self-administered bilingual questionnaire called RisPAK-Q to suit Malaysia's multiethnic and multicultural society. The attributes of preparedness measured by this instrument include the elements of risk perception (RP), attitude, and practice, 3 behavioral pillars that have long been recognized as shaping one's health behavior ${ }^{11,12}$ and the understanding of which is essential prior to designing effective interventional strategies aimed at changing the behaviors of its clients. ${ }^{13,14}$

Thus, the current study aimed to validate the newlydeveloped RisPAK-Q by measuring the validity and reliability of its constructs using both exploratory factor analysis (EFA) and confirmatory factor analysis (CFA).

\section{Methods}

The Questionnaire Development Process

The RisPAK-Q is a newly-developed questionnaire (not based on any previous local or international questionnaire). It was developed as a scoring-based, bilingual (Malay and English language), self-administered questionnaire. Forward-back translation was used to devise the bilingual form of each question. The questionnaire contained 3 main constructs with a total of 34 questions: 7 for the construct of RP (coded as item ' $\mathrm{C}$ ' in the questionnaire), 11 for attitude (coded as 'D'), and 16 for practice (coded as 'E'). A 5-point Likert scale was used to score all questions. Each question was designed so that the desired mark of each question would be 5 marks with some of the questions needing reverse marking to avoid convenient answering by the respondents. The aims of each individual construct and the details of the questions being asked are presented in Table 1 in Results section. In addition to the measured constructs, the RisPAK-Q also contained sociodemographic and travel-related information to be supplied by the respondents.

The steps used to develop the instrument was adopted from the DeVellis' scale development protocol ${ }^{15}$ :

1. Constructs development: The main constructs within the questionnaire that would measure the attributes of preparedness for travel-related infectious diseases were determined to be RP, attitude, and practice.

2. Item pool development: The construct-oriented questions (known as items) were formulated through collaboration with one field epidemiologist, 2 public health physicians, and 2 epidemiology and biostatistics academicians along with the guidelines in the Yellow Book for Traveler's Health, published by the US Center for Disease Control and Prevention (CDC), WHO Guidelines on International Travel and Health, extensive 5-year literature reviews, and established theories such as the Health Belief Model and the Theory of Planned Behavior.

3. Format ascertainment: The format of the questionnaire was determined to be in the Likert-scale form.

4. Item pool review: Each developed item was reassessed to determine its appropriateness and suitability towards the measured constructs. The content validity index (CVI) was used for item rating, with each of the expert panels rating each item as 1 for suitable or 0 for not suitable. An average of 0.6 ( 3 out of 5 points) was taken as the cut-off value to regard an item as acceptable for inclusion in the questionnaire.

5. Pretesting: The finalized questionnaire was pretested by thirty volunteers for face validation, and minor corrections were made before the validation study was conducted.

\section{Design and Data Collection}

A cross-sectional validation study was conducted involving 200 outbound Malaysian international travelers who were selected using the systematic random sampling method. The sample size was calculated using the formula of 5 respondents per item (question) to be included in the factor analysis. ${ }^{16}$ There were 34 items from 3 constructs subjected for factor analysis (construct RP, attitude, and practice); hence the calculated sample size was 170 respondents. The sample size was inflated by $20 \%$ to account for non-response; thus, the final sample size was calculated to be 200 respondents.

This study was conducted at the Kuala Lumpur International Airport (KLIA), Malaysia, from March to June, 2017. Systematically, the second and fourth week were chosen with Monday, Wednesday, and Friday of those weeks selected for data collection in the airport. The international departure gates available on the data-collection day were randomly chosen, and systematically, every second Malaysian passenger in the immigration lane was selected. The inclusion criteria were being outbound Malaysian passengers, aged 18 and above, not mentally ill, able to understand either the Malay or English language, and willing to participate with informed consent. Those who could not complete the questionnaire before boarding the flight or voluntarily resigned from completing the questionnaire at any time before boarding were excluded. Help was offered to those passengers who had problems understanding the questions; the researcher clarified the main points of the questions to them.

\section{Data Analysis}

All 34 items interspersed within the 3 different constructs were subjected to the EFA using IBM SPSS statistical software, version 22, and CFA using IBM SPSS Amos software, version 21. The EFA was conducted for factor (domain) extraction using the principal component extraction method employing Varimax rotation, with the eigenvalue set above 1 , and suppression of items with a factor loading of less than 0.4. The Kaiser-Meyer-Olkin (KMO) Index for sample adequacy and Bartlett test of sphericity were calculated. Reliability analysis was done on all extracted domains before and after any items were deleted in this stage.

The same dataset from the EFA was forwarded into the CFA. Path analysis was conducted to analyze the correlation between the items and their respective extracted domains. The correlation values were estimated using the maximum likelihood method, and the model fit was determined using the recommended model-of-fit indices: the chi-square to degree-of-freedom ratio (CMIN/DF), goodness of fit index (GFI), comparative fit index (CFI), root mean square error of approximation (RMSEA), and the standardized root mean 
Table 1. Details of the Constructs and Corresponding Questions With Mean Marks of Each Question, Construct, and overall Score ( $\mathrm{N}=173$ )

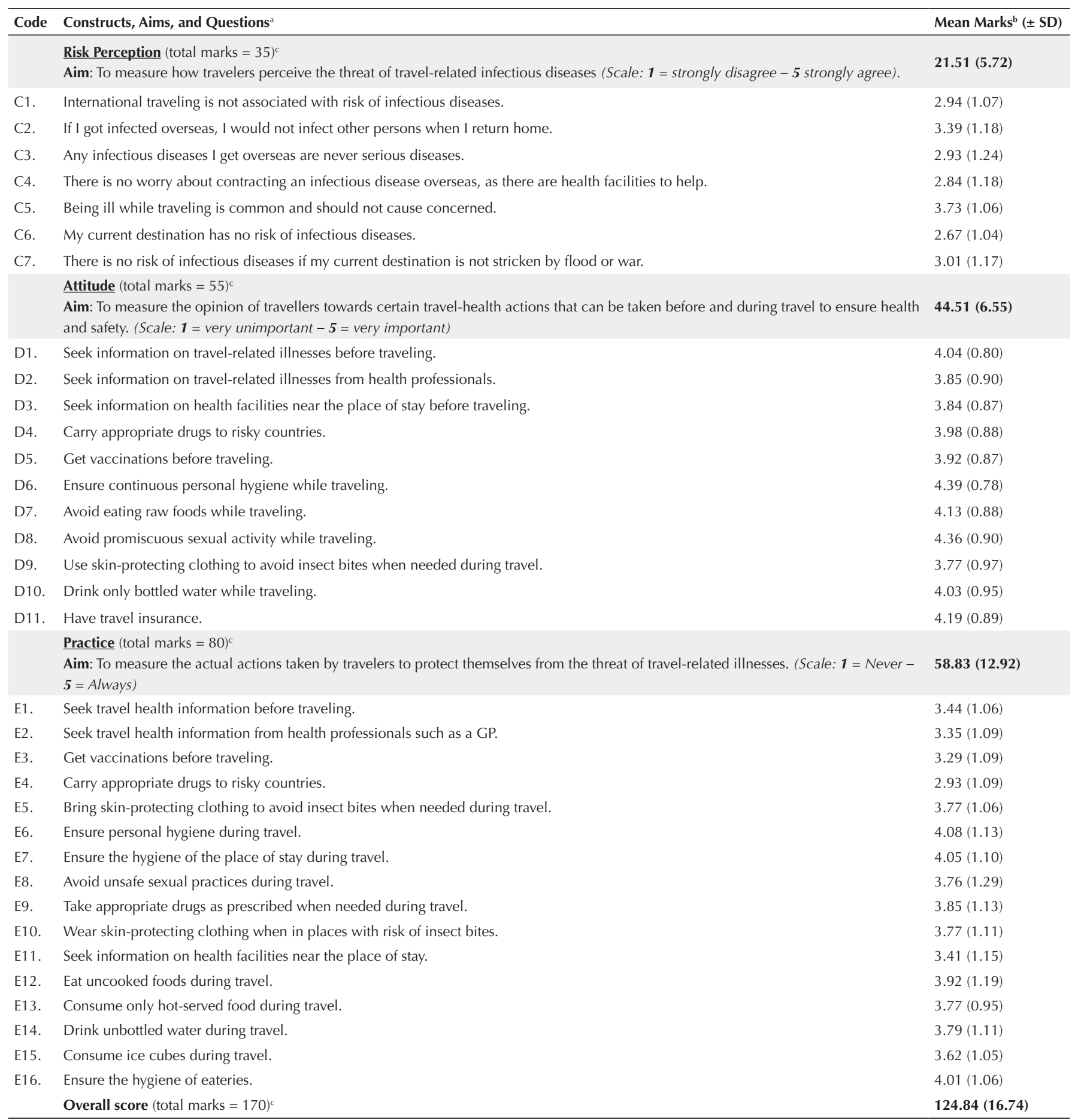

a The wording of a question in the table might differ from the actual way it was asked in the questionnaire, but the intended meanings are preserved.

${ }^{\mathrm{b}}$ The marks awarded on each response received from the respondents regarding the question. 5 marks $=$ the most desired response, 4 marks $=$ desired response, 3 marks

$=$ neutral response, 2 marks = undesired response, and 1 mark = the most undesired response.

${ }^{c}$ Total marks indicates the maximum score a respondent could get if he/she answered all questions with the most desired response.

squared residual (SRMR). ${ }^{17}$

All questions with a factor loading of less than 0.6 and several items with a modification index $(\mathrm{MI})$ value above 10 were deleted to obtain the final model with stable model fit indices. Average variance extracted (AVE) and maximum shared variance (MSV) values were calculated to determine the model's convergent and discriminant validity. To determine the model's internal consistency, the composite reliability
(CR) was calculated and compared with the conventional Cronbach $a$.

\section{Results}

\section{Respondents}

Of the 200 questionnaires distributed, 173 were completely answered and returned for analysis (response rate $=86.5 \%$ ). The age of the respondents ranged from 18 to 75 years with 
a mean age and standard deviation of $36.95 \pm 13.50$ years. Approximately $60 \%$ of the respondents were female, $49 \%$ were of Malay ethnicity, and 70\% were employed workers.

Table 1 presents the 34 questions asked of the respondents and the mean marks for individual questions, the construct, and the overall questionnaire. It shows that the majority of questions in the construct of RP had mean marks of between 2 and 3 , reflecting poor response from the respondents, while the majority of questions in the constructs of attitude and practice had mean marks of between 3 and 4, reflecting a better response by the respondents.

\section{Exploratory Factor Analysis}

The KMO index for sampling adequacy of this study was 0.865 , and the $P$ value for Bartlett test of sphericity was significant at $P<0.001$. The approximated chi-square and degree of freedom of the Bartlett test were 3702.2 and 561, respectively. The results of these indices show that the sample size employed for this validation study was adequate for running a factor analysis. ${ }^{18}$

The results of the EFA are presented in Table 2; all 34 items from the 3 constructs showed factor loadings of above 0.4 . The EFA extracted seven factors (domains) out of the 34 items whereby item C5 (RP construct) and D11 (attitude construct) loaded as isolated items into factor 6 and factor 7, respectively. Reliability analysis on all of the constructs showed Cronbach alphas of $0.844-0.941$ with all items (except C5, E4, and D11) having an item-total correlation (ITC) value of above 0.5 (Table 2).

The inter-item correlation (IIC), which indicates the correlation value of an item with the other items within the same construct, is presented in a range, whereby the IIC of items C5, D11 and E4 were mostly less than 0.4, which is less than the acceptable cutoff point (Table 2). Considering the results of the EFA, ITC, IIC, and the constructs' Cronbach $\alpha$ coefficients before and after item deletion, items C5 and D11 were deleted at this stage and not forwarded into the CFA. Item E4, however, was retained at this stage, because it loaded well into factor 4 (Table 2). The deletion of items C5 and D11 resulted in the reduction of extracted factors from seven to 5. The 5-factor solution with 32 items in the EFA was found to be accountable for $59.8 \%$ of the variance in the observed outcome of the respondents' answers on the questionnaire.

The 5 extracted factors were the RP domain (of the construct RP), pre-travel attitude (PTA) domain, duringtravel attitude (DTA) (of the construct attitude), generaltraveling practice (GP) domain and food practice (FP) (of the construct practice). The names of the factors/domains were given according to the similarity in the direction and purpose of the questions. For example, in the domain PTA, all the items grouped by the EFA (items D1, D2, and D3) were noted to revolve around travelers' attitudes towards the health-seeking actions they can take before traveling, while the domain DTA was named as such because the items under it (items D7, D8, D9, and D10) were all about the travelers' attitudes towards preventive actions they can take while traveling.

As for the domain GP, all the items factorized in it (items E5, E6, E8, E9, E10, and E11) pertained to non-focused health-related actions the travelers took to safeguard their health before and during travel. For the domain FP, all the questions (items E13, E14, E15, and E16) were about the travelers' actions regarding food intake during travel.

\section{Confirmatory Factor Analysis}

The initial path analysis in the CFA showed that the 5 domains and 32 questions obtained from the EFA had poor model fit values, with $\mathrm{CMIN} / \mathrm{DF}=2.018(P<0.001), \mathrm{GFI}=0.741, \mathrm{CFI}$ $=0.846, \mathrm{RMSEA}=0.077\left(P_{\text {Close }}<0.001\right)$, and SRMR $=0.0772$. To improve the model fit, items with a factor loading below 0.6 (C7 of domain RP and E4 of domain GP) and eight items with a MI above 10 (D4 and D5 of domain PTA, item D6 of domain DTA, items E1, E2, E3, and E7 of domain GP, and item E12 of domain FP) were deleted. The residuals of items E6 and E11 were correlated with the covariance line, since their MI were also below 10 (Figure 1). The resulting statistics improved significantly with CMIN/DF $=1.543(P<0.001)$, $\mathrm{GFI}=0.865, \mathrm{CFI}=0.945, \mathrm{RMSEA}=0.056\left(P_{\text {Close }}=0.202\right)$, and $\mathrm{SRMR}=0.057$, denoting that the final model has a 'close fit' with the data.

Figure 1 summarizes the final path analysis which retains 22 questions connected to 5 domains to represent the 3 measured constructs, i.e. RP, attitude, and practice. The factor loading of the retained items towards their respective domains (represented by a single-headed arrow connecting rectangles to ellipses) ranged from 0.62 to 0.91 . The doubleheaded arrow connecting the domains denotes the correlation values between the 5 domains. Domains of the same construct correlated strongly with each other and weakly with domains from different constructs. For example, the GP domain correlated strongly with the FP domain of the construct practice $(r=0.77)$, but it correlated weakly with the RP domain of the construct RP $(r=0.14)$ (Figure 1).

The AVE, MSV, and CR were calculated to determine the convergent/discriminant validity and reliability of each domain and are presented in Table 3. The AVE values ranged from 0.50-0.66 and were all above the cut-off value of 0.5, indicating that all 5 domains had acceptable convergent validity. ${ }^{19}$ All MSVs ranged from $0.02-0.58$, and all were below their corresponding AVEs. This result indicated that all the domains had good discriminant validity. ${ }^{20}$ The CRs of all domains ranged from $0.80-0.90$ and were comparable to their respective Cronbach $\alpha$, indicating that all the domains had good internal consistencies (Table 3). ${ }^{19}$

\section{Discussion}
Several established methods exist for validating questionnaires, including the qualitative approach ${ }^{21}$; however, validation using factor analysis involving both exploratory and confirmatory components is not uncommon and, indeed, has become more prominent recently due to its capability of producing quantitative and objective parameters for both validity and reliability aspects. ${ }^{22,23}$ While the EFA is used to factorize all the items into their common factors based on the pattern- linearity of the factor loadings, CFA complements the method by confirming and ensuring the discriminant and convergent validity (construct validity) of the extracted factors and their 
Table 2. Results of Exploratory Factor Analysis and Reliability Analysis of All 34 Items With Respective Factor Loadings, ITC, IIC, and Construct-Specific Cronbach a Before and After Item Deletion

\begin{tabular}{|c|c|c|c|c|c|c|c|c|c|c|c|c|}
\hline \multirow[t]{3}{*}{ Construct } & \multirow{3}{*}{ Item } & \multirow{2}{*}{\multicolumn{7}{|c|}{$\begin{array}{l}\text { EFA } \\
\text { Factor Loading Into Extracted Factors }\end{array}$}} & \multicolumn{4}{|c|}{ Reliability Analysis } \\
\hline & & & & & & & & & \multirow{2}{*}{ ITC $^{\mathrm{b}}$} & \multirow{2}{*}{$\mathrm{IIC}^{\mathrm{c}}$} & \multirow{2}{*}{$\mathrm{C} \alpha-1^{\mathrm{d}}$} & \multirow{2}{*}{$\mathrm{C} \alpha-2^{\mathrm{e}}$} \\
\hline & & 1 & 2 & 3 & 4 & 5 & 6 & 7 & & & & \\
\hline \multicolumn{13}{|c|}{ Risk perception } \\
\hline & $\mathrm{C} 1$ & 0.849 & & & & & & & 0.725 & $0.419-0.626$ & 0.844 & 0.851 \\
\hline & $\mathrm{C} 2$ & 0.751 & & & & & & & 0.659 & $0.385-0.626$ & & \\
\hline & $\mathrm{C} 3$ & 0.809 & & & & & & & 0.678 & $0.302-0.635$ & & \\
\hline & $\mathrm{C} 4$ & 0.725 & & & & & & & 0.598 & $0.245-0.568$ & & \\
\hline & $\mathrm{C}^{\mathrm{a}}$ & & & & & & 0.544 & & 0.393 & $0.244-0.385$ & & \\
\hline & C6 & 0.717 & & & & & & & 0.599 & $0.244-0.550$ & & \\
\hline & $\mathrm{C} 7$ & 0.662 & & & & & & & 0.559 & $0.376-0.550$ & & \\
\hline \multicolumn{13}{|l|}{ Attitude } \\
\hline & D1 & & 0.735 & & & & & & 0.619 & $0.280-0.631$ & 0.883 & 0.880 \\
\hline & D2 & & 0.860 & & & & & & 0.578 & $0.211-0.679$ & & \\
\hline & D3 & & 0.731 & & & & & & 0.694 & $0.303-0.679$ & & \\
\hline & D4 & & 0.562 & & & & & & 0.560 & $0.224-0.596$ & & \\
\hline & D5 & & 0.572 & & & & & & 0.630 & $0.284-0.596$ & & \\
\hline & D6 & & & 0.634 & & & & & 0.694 & $0.306-0.559$ & & \\
\hline & D7 & & & 0.714 & & & & & 0.562 & $0.182-0.574$ & & \\
\hline & D8 & & & 0.745 & & & & & 0.653 & $0.291-0.574$ & & \\
\hline & D9 & & & 0.726 & & & & & 0.541 & $0.205-0.593$ & & \\
\hline & D10 & & & 0.767 & & & & & 0.579 & $0.224-0.593$ & & \\
\hline & D11 ${ }^{\mathrm{a}}$ & & & & & & & 0.633 & 0.436 & $0.182-0.438$ & & \\
\hline \multicolumn{13}{|l|}{ Practice } \\
\hline & E1 & & & & 0.725 & & & & 0.588 & $0.208-0.626$ & 0.941 & - \\
\hline & E2 & & & & 0.740 & & & & 0.713 & $0.383-0.626$ & & \\
\hline & E3 & & & & 0.684 & & & & 0.614 & $0.321-0.617$ & & \\
\hline & E4 & & & & 0.408 & & & & 0.391 & $0.142-0.383$ & & \\
\hline & E5 & & & & 0.614 & & & & 0.659 & $0.396-0.588$ & & \\
\hline & E6 & & & & 0.651 & & & & 0.815 & $0.332-0.884$ & & \\
\hline & E7 & & & & 0.590 & & & & 0.789 & $0.327-0.884$ & & \\
\hline & E8 & & & & 0.590 & & & & 0.655 & $0.211-0.663$ & & \\
\hline & E9 & & & & 0.814 & & & & 0.720 & $0.300-0.641$ & & \\
\hline & E10 & & & & 0.610 & & & & 0.779 & $0.320-0.737$ & & \\
\hline & E11 & & & & 0.694 & & & & 0.651 & $0.242-0.630$ & & \\
\hline & E12 & & & & & 0.791 & & & 0.827 & $0.346-0.782$ & & \\
\hline & E13 & & & & & 0.715 & & & 0.631 & $0.142-0.684$ & & \\
\hline & E14 & & & & & 0.810 & & & 0.729 & $0.367-0.768$ & & \\
\hline & E15 & & & & & 0.737 & & & 0.645 & $0.282-0.678$ & & \\
\hline & E16 & & & & & 0.839 & & & 0.781 & $0.249-0.842$ & & \\
\hline
\end{tabular}

Abbreviations: EFA, exploratory factor analysis; ITC, item-total correlation; IIC, inter-item correlation, C $\alpha$, Cronbach Alpha.

${ }^{a}$ Bold text denotes that the item was removed from being included in the CFA.

${ }^{\mathrm{b}}$ ITC: Item-Total Correlation, indicating the correlation value between the items towards the total score of their respective constructs. The cut-off value was 0.5 .

c IIC: Inter-Item Correlation, indicating how strong an item correlated with other items of the same construct. Here, it was displayed in the range of min - max. The cut-off value was 0.4. If most of the IICs were below 0.4 (item C5, D11, E4), the item was deemed to be weakly correlated with other items of the same construct and therefore worthy of removal from the construct. However, unlike C5 and D11, item E4 was retained to be included in the CFA as it loaded well into factor 4.

${ }^{\mathrm{d}} \mathrm{C} \alpha-1$ : Cronbach's Alpha of the construct before item deletion.

${ }^{\mathrm{e}} \mathrm{C} \alpha-2$ : Cronbach's Alpha of the construct after item deletion.

respective items. ${ }^{22,24,25}$

As has been shown by the results of this study, factor analysis through CFA has complemented the other validity components of this questionnaire (the face and content validity) by proving that it also has good construct validity with acceptable discriminant and convergent validity. Moreover, CFA has also proven that this questionnaire has good internal consistencies for all of its measured domains, all of which have a CR of above 0.7 and are comparable to the conventionally calculated Cronbach a coefficient.

\section{Congruencies of the Measured Domains With Theories} and Previous Studies

The 5 measured domains in this questionnaire (RP, PTA, DTA, GP, and FP) are thematically congruent with the main components in many profound health behavior and 


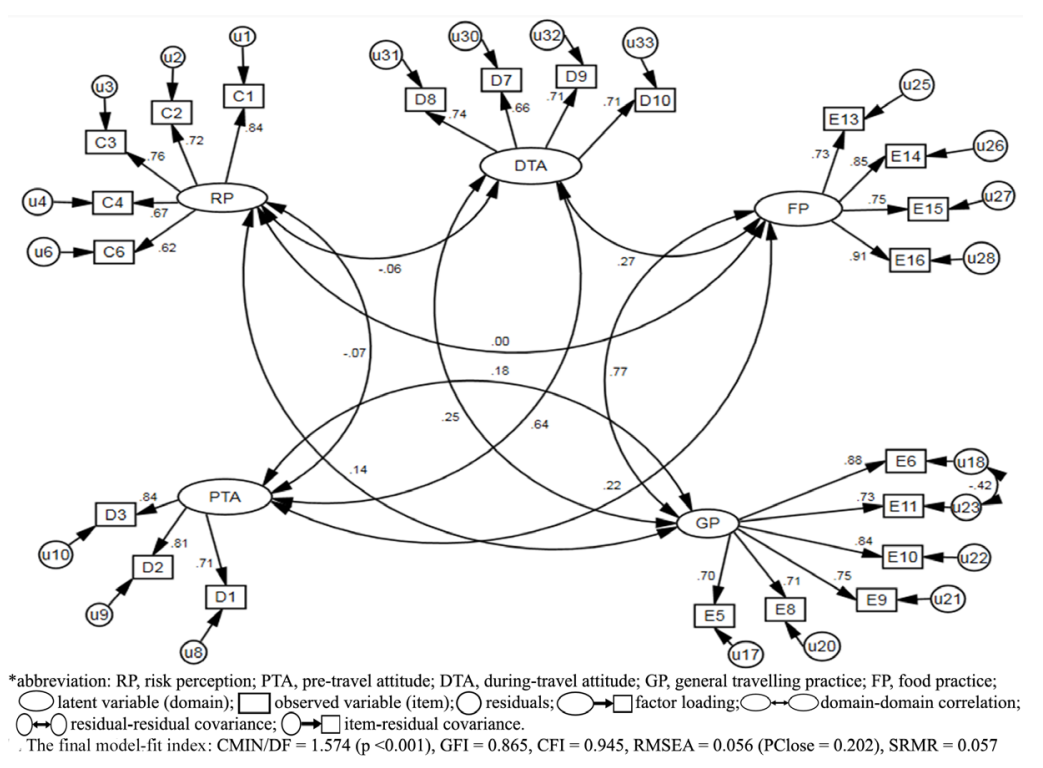

Figure 1. Path analysis of the confirmatory factor analysis (CFA) showing standardized estimates of the correlations (figures on the arrows) between the 5 domains (ellipse), the 22 items (rectangle), and their respective residuals (circle).

promotion theories and match the domains being measured either collectively or individually in many prior observational studies targeting travelers and their health-seeking behavior pertaining to preventive actions for travel-related infectious diseases.

The first validated domain in this questionnaire was $\mathrm{RP}$, which was formed as the basis for evaluating how an individual perceives the harm and risk of being inflicted by illnesses while traveling. Assessing these components of perceived susceptibility and severity of illness is essential as the fundamental of understanding one's behavior according to the distinguished Health Belief Model. ${ }^{12,26}$ This theme has also been the focus of several prior observational studies among travelers across regions, indicating the importance of measuring it in order to understand the behavior and preparedness of travelers. ${ }^{27-30}$

PTA and DTA, the 2 domains of the construct attitude in this questionnaire, were similarly the main theme measured in several other previous studies. Notably, a research conducted in the United States which particularly studied US travelers' PTAs looked specifically at the aspect of seeking health consultation before traveling and the importance of such consultation in involving specialized travel health professionals. ${ }^{31}$ Furthermore, another study investigated the DTAs of travelers in Thailand, looking particularly into the carrying of chemoprophylaxis and the use of insect-preventive measures while traveling. ${ }^{32}$ Assessing individuals' opinions or attitudes towards certain health-related preventive actions was pivotal in planning effective interventional health programs aimed at changing for the positive one's healthrelated behavior in accordance with the Theory of Planned Behavior. $^{33}$

A third and widely measured attribute of preparedness for travel-related infectious diseases in other studies was practice, which was one of the current study's main constructs. The domain GP, which was factored out of the construct, was investigated in a study in Saudi Arabia that looked into the prevalence of actual actions taken by travelers for the prevention of travel-related illness, such as ensuring the hygiene of lodgings, avoiding unsafe sexual practices, and using protection against insect bites while traveling. ${ }^{34}$ The relevance of the domain FP is based on the travel medicine recommendation by Zuckerman, who emphasized the importance of following safe eating practices while traveling to avoid travel-related, food-borne diseases. ${ }^{35}$

Nonetheless, directly comparing RisPAK-Q with other travel health questionnaires in other settings is difficult because of the non-relevance of their instruments and the lack of reports on the validation process and its parameters by other studies. A study focusing on the psychological aspects of RP among Australian travelers adopted similar validation processes involving EFA and CFA; however, the reported parameters were limited only to the RP construct with no construct validity being reported. ${ }^{36}$ Several other studies, however, have only vaguely reported on the internal consistencies of the instrument used; none have reported on the validity as a whole..$^{37,38}$

Academically, on the surface, the constructs and domains being measured in RisPAK-Q are congruent with the majority of previous studies focusing on the preparedness of travelers for travel-related infectious diseases. The depth of the questions asked within RisPAK-Q encompassing RP, attitude, and practice are inherently basic, comparable to the depth of questions being researched among Saudi Arabian, ${ }^{34}$ Emirati, ${ }^{39,40}$ and Omani travelers. ${ }^{41}$

The Pros and Cons of a Scoring-Based Instrument for Measuring Health Attributes

Contrary to many previous observational studies which employed conventional criteria to measure the prevalence 
Table 3. CFA Results With Factor Loadings of Each Item Towards Their Respective Domains and the Measurement Index for Construct Validity and Internal Consistency

\begin{tabular}{|c|c|c|c|c|c|c|c|}
\hline Construct & Domain & Item & Factor Loading & AVE & MSV & CR & $\mathrm{C} \alpha$ \\
\hline \multirow[t]{5}{*}{ Risk Perception } & RP & $\mathrm{C} 1$ & 0.845 & 0.53 & 0.02 & 0.85 & 0.84 \\
\hline & & $\mathrm{C} 2$ & 0.714 & & & & \\
\hline & & $\mathrm{C} 3$ & 0.765 & & & & \\
\hline & & $\mathrm{C} 4$ & 0.676 & & & & \\
\hline & & $\mathrm{C} 6$ & 0.616 & & & & \\
\hline \multirow[t]{7}{*}{ Attitude } & PTA & D1 & 0.712 & 0.63 & 0.41 & 0.83 & 0.83 \\
\hline & & D2 & 0.813 & & & & \\
\hline & & D3 & 0.840 & & & & \\
\hline & DTA & D7 & 0.662 & 0.50 & 0.41 & 0.80 & 0.79 \\
\hline & & D8 & 0.738 & & & & \\
\hline & & D9 & 0.709 & & & & \\
\hline & & D10 & 0.707 & & & & \\
\hline \multirow[t]{10}{*}{ Practice } & GP & E5 & 0.703 & 0.59 & 0.587 & 0.90 & 0.89 \\
\hline & & E6 & 0.863 & & & & \\
\hline & & E8 & 0.702 & & & & \\
\hline & & E9 & 0.767 & & & & \\
\hline & & E10 & 0.840 & & & & \\
\hline & & E11 & 0.744 & & & & \\
\hline & FP & E13 & 0.725 & 0.66 & 0.587 & 0.89 & 0.88 \\
\hline & & E14 & 0.853 & & & & \\
\hline & & E15 & 0.755 & & & & \\
\hline & & E16 & 0.910 & & & & \\
\hline
\end{tabular}

Abbreviation: CFA, confirmatory factor analysis; RP, risk perception; PTA, pre-travel attitude; DTA, during-travel attitude; GP, general-traveling practice; FP, food practice; AVE, average variance extracted; MSV, maximum shared variance; $C R$, composite reliability; $C \alpha$, cronbach alpha.

of travelers' preparedness and its associated factors, ${ }^{14,42,43}$ the RisPAK-Q adopts a scoring system which ultimately categorizes travelers into categories of "well-prepared" or "poorly-prepared" travelers based on their individual scores. Antithetical to criterion-referenced measurement, the advantage of this scoring system is that it simplifies risk categorization in the epidemiological context for healthcare providers, thus speeding up decision making for public health intervention. ${ }^{44,45}$

However, one caveat is that the possibility of pitfalls in the development of the scoring system for behavioral attributes (which build up the preparedness level) towards certain new health issues should not be ignored. Scoring systems that measure the attributes of preparedness for new health issues (in the context of preventing travel-related infectious diseases in Malaysia) might have disregarded the cognitive bias and social influence that could overwhelm the pre-enlightened studied population from demonstrating congruency in the observed-desired behavior. ${ }^{46}$ Consequently, the scoring system under these circumstances could have ignored the reality of certain behavior elements that do not ideally coincide in linearity with the other elements which, theoretically, should belong to similar domains. ${ }^{47}$ This, in turn, could have made the factor analysis fail to capture those important yet nonlinear behavioral elements represented by the questions that do not contribute significantly to the score of the supposed domain, resulting in their elimination in order to achieve a "close fit" model. ${ }^{24}$

Among the questions measuring the important elements of preparedness that were eliminated by factor analysis are questions D3 and D4 of the attitude construct and E3 and E4 of the practice construct. Those questions ask the travelers' attitudes and practices towards carrying appropriate drugs and getting pre-travel vaccinations, respectively (Table 1). These topics have been widely studied in other settings, reflecting their importance. In this study, it was hypothesized that, should there be some elements of travel health education being delivered in Malaysia, those important questions might have been treated differently by the factor analysis.

\section{Addressing the Shortcomings of Factor Analysis in RisPAK-Q Perspectives}

In addition to serving as a scoring instrument, the RisPAK-Q was also designed to serve as a questionnaire with some elements of a criterion-measurement tool. Those questions (D3, D4, E3 and E4) eliminated by factor analysis but regarded as important were retained as isolated questions to aid in the study of the prevalence of those particular traits in comparison with other larger studies. They will not be counted in the scoring of the RisPAK-Q. Factor analysis for the RisPAK-Q might be repeated in the future once travel health educational programs have been implemented for a certain period of time, to look for any differences in responses to these important questions.

\section{Strengths and Limitations of the Study}

The strength of this study relies primarily on the fact that it is the first validation study using a travel health questionnaire to measure the attributes of travel health behavior in Malaysia using factor analysis. Secondly, its unique bilingual concept 
significantly helped reduce the probability of information bias by improving the comprehensiveness of the questions among Malaysian respondents coming from many different ethnicities and different levels of national language proficiency. ${ }^{48,49}$ Thirdly, this study was conducted among respondents from the real population of the study (i.e. the travelers themselves), using a methodology similar to that planned for the full-scale research, in which the results obtained from this study can be extrapolated to the general Malaysian travelers.

There are also some limitations to this study. As mentioned earlier, this is the first such study to be conducted in Malaysia; hence, there are no solid local references to make a comparison possible. The limited number of international publications reporting on factor analysis of a similar topic also made the comparison of the results beyond the capacity of this study. In addition, the RisPAK-Q is a self-report questionnaire which is open to social desirability bias by the respondent, though offering anonymity (RisPAK-Q is an anonymous questionnaire) could reduce such bias to a certain degree. ${ }^{50}$ Another limitation to this study is the fact that there is no gold standard for measuring the RP, attitude, and practice of travel health; thus, the RisPAK-Q could not be tested for sensitivity and specificity. ${ }^{51}$ Since this study was conducted strictly among Malaysians, caution should be used when extrapolating the results to other populations internationally. Further validation might be needed to ascertain the usability of the RisPAK-Q in another setting.

\section{Implication on Public Health Practice}

The development and validation of this instrument are essential parts of the effort to accurately study the preparedness level of Malaysian travelers for travel-related illnesses. Such important information will be used to formulate and develop effective public health strategies to empower travelers with regard to self-prevention of travel-related illnesses, particularly infectious diseases.

\section{Conclusion}

The RisPAK-Q, which was developed methodologically in accordance with profound behavioral theories and established guidelines for travel health, has been statistically proven to be valid and reliable. It could be used as an instrument in a larger study to measure the attributes of preparedness for travelrelated infectious diseases among Malaysian international travelers in terms of prevalence and associated factors. The knowledge then could be used to strategically develop public health interventional programs targeting travelers and their health aspects accordingly.

\section{Authors' Contributions}

MHG was involved in the conception of the study design, development of the questionnaire, data collection, data analysis, and drafting the manuscript. SAS contributed equally to the conception of the study design, development of the questionnaire, and data analysis. MIM contributed to the data analysis and refinement of the draft. All authors jointly reviewed the manuscript for approval of the final draft and submission to this journal.

\section{Research Highlights}

\section{What Is Already Known?}

Little is known about travel health in Malaysia. To date, there is no validated instrument in place for conducting relevant research into travel health in this country.

\section{What This Study Adds?}

In addition to validating a novel measurement tool for measuring travel health awareness and preparedness among Malaysian travelers, this study also adds to:

1. The knowledge on conducting comprehensive and holistic validation studies of a newly-developed questionnaire, particularly using factor analysis;

2. The understanding of travel health components that are actually made up of several more focused domains, at least contextual to the local setting of Malaysia;

3. The credence of quality data and information that can be obtained from future studies using this validated questionnaire, especially for Malaysian public health providers in formulating strategies to establish specialized travel health services in the country.

\section{Conflict of Interest Disclosures}

None declared.

\section{Ethical Approval}

The conducting of this study conformed to the ethical considerations outlined in the Declaration of Helsinki (1975) and was approved by the Research Ethics Committee of the Universiti Kebangsaan Malaysia (UKM PPI/111/8/JEP-2016553). Participation in this study was strictly voluntary, and informed consent was obtained from each of the respondents.

\section{Funding/Support}

This work was supported by the Universiti Kebangsaan Malaysia (UKM) (Grant No: FF-2016-282).

\section{Acknowledgments}

The authors thank all travellers who participated in this study and the Kuala Lumpur International Airport (KLIA) Health Office and general management for granting permission for data collection in the airports.

\section{References}

1. Knobler S, Mahmoud A, Lemon S. The Impact of Globalization on Infectious Disease Emergence and Control: Exploring the Consequences and Opportunities: Workshop Summary. Washington (DC): National Academies Press; 2006.

2. World Tourism Organization (UNWTO). World Tourism Barometer. 2017:13.

3. World Tourism Organization (UNWTO). 2017 International Tourism Results: The Highest in Seven Years. http://media.unwto.org/pressrelease/2018-01-15/2017-international-tourism-results-highestseven-years. 2018.

4. Allen KC. Tracking the traveler without a passport: perspective on surveillance of imported disease. J Travel Med. 2014;21(5):295-297. doi:10.1111/jtm.12143.

5. Talbot EA, Chen LH, Sanford C, McCarthy A, Leder K. Travel medicine 
research priorities: establishing an evidence base. J Travel Med. 2010;17(6):410-415. doi:10.1111/j.1708-8305.2010.00466.x.

6. Behrens RH, Carroll B. The challenges of disease risk ascertainment using accessible data sources for numbers of travelers. J Travel Med. 2013;20(5):296-302. doi:10.1111/jtm.12062.

7. Leder K, Torresi J, Libman MD, et al. GeoSentinel surveillance of illness in returned travelers, 2007-2011. Ann Intern Med. 2013;158(6):456-468. doi:10.7326/0003-4819-158-6-20130319000005.

8. Stoddard ST, Morrison AC, Vazquez-Prokopec GM, et al. The role of human movement in the transmission of vector-borne pathogens. PLoS Negl Trop Dis. 2009;3(7):e481. doi:10.1371/journal. pntd.0000481.

9. Liu SJ, Sharapov U, Klevens M. Patient awareness of need for hepatitis a vaccination (prophylaxis) before international travel. J Travel Med. 2015;22(3):174-178. doi:10.1111/jtm.12186.

10. Warne B, Weld LH, Cramer JP, et al. Travel-related infection in European travelers, EuroTravNet 2011. JTravel Med. 2014;21(4):248254. doi:10.1111/jtm.12120.

11. Bettinghaus EP. Health promotion and the knowledgeattitude-behavior continuum. Prev Med. 1986;15(5):475-491. doi:10.1016/0091-7435(86)90025-3.

12. Ferrer R, Klein WM. Risk perceptions and health behavior. Curr Opin Psychol. 2015;5:85-89. doi:10.1016/j.copsyc.2015.03.012.

13. Hassali MA, Saleem F, Shafie AA, et al. Perception towards health promotion activities: Findings from a community survey in the state of Penang, Malaysia. Malaysian J Public Health Med. 2012;12(2):614.

14. Pfeil A, Mutsch M, Hatz C, Szucs TD. A cross-sectional survey to evaluate knowledge, attitudes and practices (KAP) regarding seasonal influenza vaccination among European travellers to resource-limited destinations. BMC Public Health. 2010;10:402. doi:10.1186/1471-2458-10-402.

15. DeVellis RF. Scale Development: Theory and Applications. Thousand Oaks, Calif: Sage Publications; 2003.

16. MacCallum RC, Widaman KF, Zhang S, Hong S. Sample size in factor analysis. Psychol Methods. 1999;4(1):84-99. doi:10.1037/1082989X.4.1.84.

17. Byrne BM. Structural Equation Modeling With AMOS: Basic Concepts, Applications, and Programming. 2nd ed. New York: Routledge; 2010.

18. Hof M. Questionnaire evaluation with factor analysis and Cronbach's alpha. http://www.let.rug.nl/nerbonne/teach/remastats-meth-seminar/student-papers/MHof-QuestionnaireEvaluation2012-Cronbach-FactAnalysis.pdf. Published 2012

19. Malhotra NK, Birks DF. Marketing Research: An Applied Approach. 3rd ed. London: Prentice Hall/Financial Times; 2007.

20. Hair JF Jr, Black WC, Babin BJ, Anderson RE, Tatham RL. Multivariate Data Analysis. Pearson; 2010.

21. Ratnam I, Torresi J, Matchett E, et al. Development and validation of an instrument to assess the risk of developing viral infections in Australian travelers during international travel. J Travel Med. 2011;18(4):262-270. doi:10.1111/j.1708-8305.2011.00533.x.

22. Mahmood MI, Shah SA, Ahmad N, Rosli NM. Cancer Screening Perception Scale: Development and Construct Validation. J Cancer Educ. 2018;33(2):269-277. doi:10.1007/s13187-016-1081-7.

23. Raval VV, Ward RM, Raval PH, Trivedi SS. Confirmatory and Exploratory Factor Analyses of Parental Authority Questionnaire in Urban India. J Child Fam Stud. 2013;22(5):707-718. doi:10.1007/ s10826-012-9624-y.

24. Squires JE, Estabrooks CA, Newburn-Cook CV, Gierl M. Validation of the conceptual research utilization scale: an application of the standards for educational and psychological testing in healthcare. BMC Health Serv Res. 2011;11:107. doi:10.1186/1472-6963-11107.

25. Williams B, Onsman A, Brown T. Exploratory factor analysis: A five-step guide for novices. Australasian Journal of Paramedicine. 2012;8(3):1-13.

26. Stretcher V, Rosenstock IM. The Health Belief Model. In: Glanz K,
Lewis FM, Rimer BK, eds. Health Behaviour and Health Education: Theory, Research and Practice. San Francisco: Jossey-Bass; 1997.

27. Provost S, Soto JC. Perception and knowledge about some infectious diseases among travelers from Quebec, Canada. J Travel Med. 2002;9(4):184-189. doi:10.2310/7060.2002.24550.

28. Zimmermann R, Hattendorf J, Blum J, Nuesch R, Hatz C. Risk perception of travelers to tropical and subtropical countries visiting a swiss travel health center. J Travel Med. 2013;20(1):3-10. doi:10.1111/j.1708-8305.2012.00671.x.

29. Hartjes LB, Baumann LC, Henriques JB. Travel health risk perceptions and prevention behaviors of US study abroad students. J Travel Med. 2009;16(5):338-343.doi:10.1111/j.1708-8305.2009.00322.x.

30. El-Ghitany EM, Mohamed Abdelmohsen MA, Farghaly AG, Abd El-Gawwad E, Abd El-Wahab EW. Travel Health Survey: Risk Perception, Health-Seeking Behavior, and Subjective Evaluation of Travel Health Services in Egypt. Int J Travel Medicine Glob Health. 2018;6(1):16-24. doi:10.15171/ijtmgh.2018.04.

31. Hamer DH, Connor BA. Travel health knowledge, attitudes and practices among United States travelers. JTravel Med. 2004;11(1):2326. doi:10.2310/7060.2004.13577.

32. Piyaphanee $\mathrm{W}$, Wattanagoon $\mathrm{Y}$, Silachamroon $\mathrm{U}$, Mansanguan $\mathrm{C}$, Wichianprasat P, Walker E. Knowledge, attitudes, and practices among foreign backpackers toward malaria risk in southeast Asia. J Travel Med. 2009;16(2):101-106. doi:10.1111/j.17088305.2008.00282.x.

33. Barber JS. The Theory of Planned Behaviour: considering drives, proximity and dynamics. Vienna Yearb Popul Res. 2011;9:31-35. doi:10.1553/populationyearbook2011s31.

34. Alghamdi AH, Ibrahim AM, Al-Ghamdi MS, Ryan ET, Al-Raddadi R. Travel Health in the Kingdom of Saudi Arabia: Perception and Practice of Saudi Travelers. International Journal Of Health Research And Innovation. 2014;2(2):25-39.

35. Zuckerman JN. Principles and Practice of Travel Medicine. Wiley; 2001. doi:10.1002/0470842512.

36. Chien PM, Sharifpour M, Ritchie BW, Watson B. Travelers' Health Risk Perceptions and Protective Behavior: A Psychological Approach. J Travel Res. 2017;56(6):744-759. doi:10.1177/0047287516665479.

37. Chen CM, Tsai JS, Chen SH, Lee HT. Knowledge, attitudes, and practices concerning infection control among travelers between Taiwan and mainland China. Asia Pac J Public Health. 2011;23(5):712720. doi:10.1177/1010539511419118.

38. Han P, Balaban V, Marano C. Travel characteristics and risk-taking attitudes in youths traveling to nonindustrialized countries. J Travel Med. 2010;17(5):316-321. doi:10.1111/j.1708-8305.2010.00444.x.

39. Omer F, Hassan N, Hussain H, Mana S, Awad O. Travel health, gaps in knowledge, attitudes, and practices among Dubai travellers, Dubai UAE. Int J Prev Med Res. 2015;1(3):126-131.

40. Ismayl G, Abdel Hadi H, Hussein A, et al. Practices and attitudes to prevention of travel-related infectious diseases in United Arab Emirates. Int J Travel Medicine Glob Health. 2016;4(1):13-18. doi:10.20286/ijtmgh-040113.

41. Al-Abri SS, Abdel-Hady DM, Al-Abaidani IS. Knowledge, attitudes, and practices regarding travel health among Muscat International Airport travelers in Oman: Identifying the gaps and addressing the challenges. J Epidemiol Glob Health. 2016;6(2):67-75. doi:10.1016/j.jegh.2016.02.003.

42. Wilder-Smith A, Khairullah NS, Song JH, Chen CY, Torresi J. Travel health knowledge, attitudes and practices among Australasian travelers. J Travel Med. 2004;11(1):9-15. doi: $10.2310 / 7060.2004 .13600$

43. Toovey S, Jamieson A, Holloway M. Travelers' knowledge, attitudes and practices on the prevention of infectious diseases: results from a study at Johannesburg International Airport. J Travel Med. 2004;11(1):16-22. doi:10.2310/7060.2004.13587.

44. Furlong WJ, Feeny DH, Torrance GW, Barr RD. The Health Utilities Index (HUI) system for assessing health-related quality of life in clinical studies. Ann Med. 2001;33(5):375-384. doi:10.3109/07853890109002092.

45. Yost I, Dobbins M, Traynor R, DeCorby K, Workentine S, Greco L. 
Tools to support evidence-informed public health decision making. BMC Public Health. 2014;14:728. doi:10.1186/1471-2458-14-728.

46. Wang XT, Simons F, Bredart S. Social cues and verbal framing in risky choice. J Behav Decis Mak. 2001;14(1):1-15. doi:10.1002/10990771(200101)14:1<1::AID-BDM361>3.0.CO;2-N

47. Krosnick JA, Judd CM, Wittenbrink $B$. The measurement of attitudes. In: Allbarracin D, Johnson BT, Zanna MP, eds. Handbook of attitudes and attitude change. Mahwah, NJ: Erlbaum; 2005:21-76.

48. Potaka L, Cochrane S. Developing bilingual questionnaires: Experiences from New Zealand in the development of the 2001 Maori language survey. J Off Stat. 2004;20(2):289-300.
49. Antshel KM. Integrating culture as a means of improving treatment adherence in the Latino population. Psychol Health Med. 2002;7(4):435-449. doi:10.1080/1354850021000015258.

50. Paulhus DL. Socially Desirable Responding: The Evolution of a Construct. In: Braun HI, Jackson DN, Wiley DE, eds. The Role of Constructs in Psychological and Educational Measurement. New Jersey: Lawrence Erlbaum Associates Publishers; 2002:49-69.

51. Toft $N$, Jorgensen E, Hojsgaard S. Diagnosing diagnostic tests: evaluating the assumptions underlying the estimation of sensitivity and specificity in the absence of a gold standard. Prev Vet Med. 2005;68(1):19-33. doi:10.1016/j.prevetmed.2005.01.006. 